\title{
Manipulating word properties: Targeting vocabulary learning for children with and without speech sound inaccuracies
}

Child Language Teaching and Therapy 28(I) $|0|-12 \mid$ (C) The Author(s) 2011 Reprints and permission: sagepub. co.uk/journalsPermissions.nav DOI: $10.1177 / 026565901 \mid 432015$ clt.sagepub.com @SAGE

\author{
Kimberly D McDowell and Jeri Carroll \\ Wichita State University, KS, USA
}

\begin{abstract}
The purpose of this study was twofold: (I) to examine the relations between speech sound accuracy, vocabulary, and phonological awareness, and (2) to examine the effect of word properties of neighborhood density and phonotactic probability on word learning within a storybook context, for children with and without speech sound inaccuracies. Fifty $\mathrm{K}-\mathrm{I}$ children (aged 5-6 years; 25 with, 25 without speech sound inaccuracies) completed inclusionary measures of oral language, speech sound accuracy, hearing screening, oral-motor screening, and nonverbal intelligence. Participants completed study-specific measures of standardized receptive and expressive vocabulary, stimuli-specific vocabulary knowledge, and phonological awareness. Twice weekly, for 30 minutes, an II-week storybook-based intervention took place, targeting word learning, with words selected based on density and probability. Storybooks were researcher generated to intentionally manipulate the word properties of the stimuli words. Each storybook contained two stimuli words, four exposures per word per reading. Results indicated that both speech sound accuracy and vocabulary predicted unique variance in phonological awareness in children with speech sound inaccuracies. No statistically significant differences in the absolute number of words children learned emerged. Group differences were noted in emerging word knowledge with typically developing children outperforming children with speech sound inaccuracies. Differences were noted in the types of words that children learned. Results suggest that children with speech sound inaccuracies may be at risk for later reading difficulties. Speech language pathologists need to be targeting words that promote change within a child's phonological system (sublexical) and his/her lexical system.
\end{abstract}

\section{Keywords}

preschool, vocabulary, phonological awareness, word properties, speech sound accuracies/ inaccuracies, articulation, storybook intervention 


\section{Introduction}

This article seeks to address issues regarding efficient and effective use of key vocabulary words to target within a storybook context for children with and without speech sound inaccuracies. The primary areas focused on in the literature review are:

1. the relations between vocabulary and phonological awareness;

2. word learning and linguistic factors within words that may impact word learning and the purported differences in word learning among children with and without speech sound inaccuracies; and

3. storybook interventions as a context for word learning.

Given extant literature, there are several unanswered questions regarding these topics. Primarily, does growth in vocabulary facilitate growth in phonological awareness skills as children are restructuring their lexicons? Second, are there differences in the types of words (i.e. lexical properties) that children in early elementary school (i.e. $\mathrm{K}-1$ ) with and without speech sound inaccuracies learn? If so, how does this impact the relation between vocabulary and phonological awareness? The specific aims of this study were:

- to further explore the nature of the relation between vocabulary and phonological awareness in children with and without speech sound inaccuracies; and

- to determine whether word properties (i.e. phonotactic probability and neighborhood density) impact word learning in children with and without speech sound inaccuracies.

\section{Review of the literature}

\section{Relation between vocabulary and phonological awareness}

The National Reading Panel (2000) identified five essential components for successful reading acquisition. Extant research, however, indicates that these skills may not be discrete and separable. For example, efforts to identify the causes of the development of phonological awareness (and subsequent phonemic awareness) have not yielded consistent findings (Raz and Bryant, 1990; Sénéchal and Lefevre, 2002). One possible origin for the development of phonological awareness may be the development of vocabulary. Current research indicates that phonological awareness and oral language skills are significantly correlated in the preschool period (Lonigan et al., 1998; Roth et al., 2002), that there are significant concurrent and longitudinal associations between vocabulary and phonological awareness (Cooper et al., 2002), and that some data suggest that vocabulary is predictive of growth in phonological awareness (Lonigan, 2006).

There are correlational studies indicating significant concurrent and longitudinal associations between children's vocabulary skills and their phonological awareness skills (Cooper, et al., 2002; Wagner and Torgesen, 1987). In a recent reanalysis (Lonigan, 2006), 286 preschool children were randomly assigned to one of five conditions. The intervention conditions consisted of partially crossed combinations of oral language intervention, phonological awareness intervention, and print knowledge versus control. For the reanalysis, Lonigan created groups of children: (1) those who had received oral language intervention (vs. those who had not), and (2) those who had received phonological awareness intervention (vs. those who had not). Results indicated that children who received the oral language intervention experienced significantly more growth in vocabulary than those in the control condition. In addition, those children in the oral language group experienced significantly more growth in phonological awareness skills than those who did not receive the oral language intervention. For those in the phonological awareness group, significant differences in 
phonological awareness growth were evident; however, there was a lack of a cross-over effect on the phonological awareness intervention on vocabulary. Results from this reanalysis support the notion that 'vocabulary development is causal in the development of phonological awareness' (Lonigan, 2006: 27). What this study did not examine were the impact that word properties had on word learning and prediction of phonological awareness growth and the relations among these skills in children with speech sound inaccuracies (Edwards et al., 2002).

\section{Word learning and potential linguistic factors impacting learning}

a Word learning: In terms of word learning, children may begin as 'whole' word learners but quickly learn adult-like phonetic features and segments, allowing easier and more efficient access to their lexicons. As a child's lexicon grows in size and complexity, the child is faced with a need for a more specific phonological representation of spoken words so that access and retrieval are quick and accurate (Metsala, 1997; Storkel and Morrisette, 2002). Metsala and Walley (1998) have proposed that this segmental representation is, in part, the product of the development of vocabulary. Their lexical restructuring model (LRM) was formulated to account for developmental changes in the structure of spoken word representations and the growth of phonological awareness. According to this model, the representations supporting spoken word recognition become increasingly segmental with spoken vocabulary growth, and this change makes possible explicit access to phonemic units (Walley et al., 2003).

Variations across children in lexical growth and in the restructuring process may contribute to individual differences in phonological awareness, and thus success in learning to read an alphabetic orthography. Although typically developing children appear to restructure their lexicons from whole word lexical representations to phonemic level representations, it is unclear whether speech sound accuracy affects this ability. As children are learning words, they are also learning sounds.

When examining word learning, it is important to consider the level of representation of a word. The phonological (or sublexical) representation refers to the individual phonemes that comprise a word, with each phoneme being seen as a separate entity (Vitevitch and Luce, 1999). In contrast, the lexical representation refers to the word's sound sequence as a whole unit (Vitevitch and Luce, 1999). Additionally, Storkel (2004) points out that children must simultaneously learn the sublexical, lexical, and semantic (i.e. the word's meaning) representations. Given this parallel acquisition, it could be that the development of or acquisition of the semantic representation may facilitate the emergence of the sound, or sublexical representation.

b Linguistic factors: Two properties of word forms appear to impact language processing: phonotactic probability and neighborhood density. Phonotactic probability refers to the likelihood of occurrence of a given sound pattern (Vitevitch and Luce, 1998). Additionally, words in the lexicon can be thought of as being arranged based on lexical similarity, or differing by only one phoneme (Luce and Pisoni, 1998; Storkel, 2002). Words that are similar to only a few other words are said to be housed in sparse neighborhoods (e.g. fish). In contrast, words that are phonologically similar to many words are said to be housed in dense neighborhoods (e.g. car).

Importantly, some children experience delays or deficits in the acquisition of accurate speech sound productions in the absence of any concomitant social, cognitive, or motor deficit (Shriberg et al., 1986). Current research indicates that children with speech sound disorders are at risk for reading-related difficulties (Bird et al.n, 1995; McDowell et al., 2007).

It is thought that these children have different underlying phonological representations compared to typically developing peers (Elbro, 1996; McDowell et al., 2007). For this reason, children with speech sound inaccuracies may not use phonological representations to learn new words, thus 
impacting the restructuring process (and subsequent emergence of phonological awareness). There have been a few studies examining the impact of phonological awareness training on the speech accuracy, phonological processing, and reading skills of children with speech inaccuracies (e.g. Gillon, 2000; Rvachew et al., 2004). Some of the research has included children with spoken language impairment, thus not eliminating or controlling for the issue of oral language (Gillon, 2000). This is an important variable to consider if one is interested in examining the role the semantic representation may have on the sublexical. Findings from this line of research indicate that interventions focusing on phonological awareness skills can positively impact speech accuracy as well as phonological awareness skills.

Several studies have examined the use of vocabulary intervention as a method for facilitating growth in phonological awareness. These studies have varied in the use of context, with some being conducted in a lab or clinic (Mendelsohn et al., 2001) and others being conducted in the classroom (Whitehurst et al., 1994). They have also varied in delivery, with some involving parents (CrainThorenson and Dale, 1999; Lonigan and Whitehurst, 1998), teachers (Lonigan and Whitehurst, 1998), or researchers (Justice et al., 2005; Storkel, 2005) as the interventionist. They have included typically developing children (Coyne et al., 2007), children with language impairments or impaired vocabulary (Hargrave and Sénéchal, 2000; Justice et al., 2005), and children from homes of low socioeconomic status (Whitehurst et al., 1994). They have included real words (Hoover et al., 2008; Justice et al., 2005; Maekawa and Storkel, 2005) and non-words (Hoover et al., 2008; Storkel, 2001, 2004). Finally, they differ in the materials used to stimulate word learning, with some using referents/ objects (Storkel, 2001, 2004; Storkel et al., 2007) and some using storybooks (Justice et al., 2005; Storkel, 2001, 2004). A few have included children with phonological delays (Storkel, 2004; Maekawa and Storkel, 2005), but these have been preschool children. What has not been examined is how the manipulation of word properties within a storybook context impacts word learning in early elementary-aged (i.e. K-1) students with speech sound inaccuracies. The remaining questions are whether differences in vocabulary and phonological awareness may be attributed to differences in the speech sound accuracy and whether speech sound accuracy could be predictive of phonological awareness, controlling for oral language.

\section{Word learning interventions: Manipulation of word properties}

Literature is scant in the investigation of word learning based on word properties in early elementaryaged (i.e. $\mathrm{K}-1$ ) students. Although two general threads of literature exist - those focusing on adults and those focused on preschool students - only the studies focusing on preschoolers are provided.

Targeting preschool word learning, Storkel et al. (2006) examined the lexical and sublexical representations of preschool children with and without phonological disorders. Participants included 17 children with and 17 children without phonological disorders. Children participated in a shortterm word-learning task with 16 non-words (sublexical), fully crossed for probability and density (four per density/probability condition). Additionally, a long-term word-learning task that involved 121 real words (lexical) fully crossed for density and probability was utilized. Assessment involved an expressive picture naming task and a receptive pointing task. Results indicated that differences in word learning were observed based on phonological development. Children with phonological inaccuracies did not show an effect of phonotactic probability on long-term word learning. This is in contrast to children with typically developing productive phonologies.

Similarly, Storkel et al. (2007) examined word learning in preschool children with phonological delays. Participants included 20 children with and 20 children without phonological delays. Participants engaged in a word learning, picture naming task with 24 exposures. Results indicated 
that children with phonological delays differed from typically developing children in word learning in that these children learned fewer words during the immediate learning task. The authors concluded that productive phonology may influence the immediate processing of new words.

These studies with preschool children provide insight into the result of word learning and the foundation that may lead to word-level reading difficulties upon entry into formal education. However, no known intervention study that has focused on manipulation of lexical properties to impact word learning has been conducted with primary grade students (aged 6-7 years). Storkel's work (2001, 2004) has focused primarily on preschool children. Vitevitch's work (1999) has focused on adults. Given that there is an increased focus on kindergarten (aged 5-6 years) through third grade (aged 8-9 years) reading skills with No Child Left Behind legislation, the need for a study using children within these grades became apparent.

\section{Storybook interventions}

Storybook-based interventions have been shown to be effective for providing a supportive, contextualized environment for targeting many areas predictive of later academic success (Justice and Ezell, 2002). Kaderavek and Justice (2002) provided speech-language pathologists with guidelines for overcoming some of the potential pitfalls when using storybook-based interventions. Storybook-based interventions have been used to facilitate change in parental behaviors (Justice and Ezell, 2002), phonological awareness (Ziolkowski and Goldstein, 2008), print awareness (Justice and Ezell, 2002), oral language (Lonigan and Whitehurst, 1998) and, specifically, vocabulary (Coyne et al., 2004; Justice et al., 2005). These studies indicate that word learning can be targeted within a storybook reading context. What remains to be examined is manipulation of the word properties within the intervention and how that impacts word learning in typically developing children and in children with speech sound deficits.

\section{Preliminary study}

The goal of the preliminary study (McDowell, 2004) was to determine if speech sound accuracy moderated the relation between vocabulary and phonological awareness. Vocabulary, speech sound accuracy, and phonological awareness skills were examined in a group of 140 elementary students ( $\mathrm{K}-2$ grades). The students ranged in age from 5 years, 2 months old to 8 years, 7 months old $(M=6$ years, 8 months, $S D=9.7$ months). The children completed one formal measure of vocabulary ( $P P V T$ $3)$, one informal measure of vocabulary (story retelling with type-token ratio calculated), two speech sound accuracy measures (percent consonant correct from story retelling transcription and a multisyllabic word repetition task), and two measures of phonological awareness (Blending and Elision from the Comprehensive Test of Phonological Processes; CTOPP; Wagner et al., 1998). Simultaneous regression was employed to determine if vocabulary and/or speech sound accuracy predicted phonological awareness. The model was statistically significant, $F(2,138)=20.93, p=.001$, and accounted for $31 \%$ of the variance in phonological awareness. Vocabulary accounted for $14 \%$, and speech sound accuracy accounted for $15 \%$ of the unique variance. Hierarchical multiple regression analyses were then performed to test the prediction that speech sound accuracy moderated the relation between phonological awareness and vocabulary. The model was statistically significant, $F(1,139)=11.78$, $p=.001$, and the interaction term accounted for an additional $4 \%$ of the unique variance in phonological awareness. These results indicate that the effect of vocabulary on phonological awareness is moderated by speech sound accuracy. What remains to be seen is whether vocabulary growth can facilitate growth in phonological awareness in children with speech sound inaccuracies. 


\section{Specific aims}

The goal of this research was to understand the relation between vocabulary and phonological awareness skills in school-aged children. Recent evidence suggests that as typically developing children acquire new words, their lexicons restructure from lexical representations at the holistic (word) level to lexical representations at smaller levels (e.g. syllable, onset rime, phoneme). Two notions remain less clear: (1) whether this restructuring leads to the emergence of phonological awareness, and (2) whether children who have speech sound inaccuracies are able to take advantage of this restructuring process in the same way as typically developing peers. The specific aims of the current research project were (1) to further explore the nature of the relation between vocabulary and phonological awareness in children with and without speech sound inaccuracies, and (2) to determine whether word properties (i.e. phonotactic probability and neighborhood density) impact word learning in children with and without speech sound inaccuracies.

\section{Method}

\section{Participants}

Children between the ages of 5;2 and 6;6 (K-1) were recruited from local school through a teacher nomination process. All students were native English speakers. Teachers were provided with an overview of the study (i.e. storybook reading to enhance vocabulary skills) and then asked to nominate students into two different groups: those with typical speech and those with speech sound inaccuracies. This age group was selected as participants given that it is an age of phonological and lexical growth (e.g. Anglin, 1993). Those who were recruited completed inclusionary assessments to determine the accuracy of placement (see Table 1). There were 32 nominated into the typical group (typical) and 27 nominated into the group of students with speech sound inaccuracies (SSI). These placements were confirmed or refuted through inclusionary assessments. Those who met inclusionary criteria then completed the study-specific assessments (see Table 1).

\section{Measures}

a Inclusionary measures: Inclusionary criteria for typically developing participants included scores within one standard deviation of the mean on the Goldman Fristoe Test of Articulation 2 (GFTA-2; Goldman and Fristoe, 2000), and scores within one standard deviation of the mean on standardized measures of oral motor skills (Oral Speech Mechanism Screening Examination-3 or OSME-3; St Louis and Ruscello, 2000), receptive and expressive language (Oral and Written Language Scales or OWLS; Carrow-Woolfolk, 1995), and nonverbal intelligence (Performance subtests from the Weschler Preschool and Primary Scale of Intelligence Third Edition or WPPSI-3; Weschler, 2002). Inclusionary criteria for participants with speech sound inaccuracies included the above, with the exception of speech sound inaccuracies as evidenced by performance at least one standard deviation below the mean on the GFTA-2. A final sample of 25 typically developing participants and 25 participants with speech sound inaccuracies completed study-specific measures. This number of participants is based on effect sizes from similar studies (e.g. Storkel, 2004; $d=.56$ ) and a power of .80 .

b Study-specific measures: In addition to the inclusionary measures, participants completed studyspecific measures. To measure phonological awareness, the Elision and Blending subtests from the CTOPP (Wagner et al., 1998) were administered. They also completed formal measures of receptive and expressive vocabulary and were given the PPVT-3 (Dunn and Dunn, 1997) and the Expressive Vocabulary Test (EVT; Williams, 1997). 
Table I Overview of measures

\begin{tabular}{|c|c|c|}
\hline Variable & Measure & Psychometric properties \\
\hline \multicolumn{3}{|c|}{ Inclusionary measures: } \\
\hline Language & $\begin{array}{l}\text { Oral and Written Language Scale (OWLS; Carrow- } \\
\text { Woolfolk, 1995) }\end{array}$ & \multirow[t]{2}{*}{$\begin{array}{l}\text { Reliability coefficient of .91 } \\
\text { for total language scale }\end{array}$} \\
\hline Hearing & Bilateral hearing screening at $20 \mathrm{~dB} \mathrm{HL}$ at $1,000-4,000 \mathrm{~Hz}$ & \\
\hline $\begin{array}{l}\text { Speech } \\
\text { sound } \\
\text { accuracy }\end{array}$ & $\begin{array}{l}\text { Goldman Fristoe Test of Articulation, 2nd edition (GFTA-2; } \\
\text { Goldman and Fristoe, 2000) }\end{array}$ & $\begin{array}{l}\text { Reliability coefficients of } \\
.96 \text { for females, } .95 \text { for } \\
\text { males }\end{array}$ \\
\hline \multirow[t]{2}{*}{ Oral motor } & Motor Oral Speech; Mechanism Screening & \multirow[t]{2}{*}{ Unavailable } \\
\hline & Examination-3 (OSMSE-3; St Louis and Ruscello, 2000) & \\
\hline $\begin{array}{l}\text { Nonverbal } \\
\text { intelligence }\end{array}$ & $\begin{array}{l}\text { Performance subtests from the Wechsler Preschool } \\
\text { and Primary Scale of Intelligence, 3rd edition (WPPSI-III; } \\
\text { Wechsler, 2002) }\end{array}$ & $\begin{array}{l}\text { Reliability coefficients range } \\
\text { from } .83 \text { to } .95 \text {; for the } \\
\text { performance subtests, } .87\end{array}$ \\
\hline \multicolumn{3}{|c|}{ Study-specific measures: } \\
\hline Vocabulary & $\begin{array}{l}\text { I. Peabody Picture Vocabulary Test-III (PPVTIII; Dunn and } \\
\text { Dunn, 1997) } \\
\text { 2. Expressive Vocabulary Test (EVT; Williams, 1997) }\end{array}$ & $\begin{array}{l}\text { Median internal } \\
\text { consistencies of } .95 \text { for } \\
\text { both I. and } 2 \text {. }\end{array}$ \\
\hline $\begin{array}{l}\text { Phonological } \\
\text { awareness }\end{array}$ & $\begin{array}{l}\text { Elision and Blending subtests of the Comprehensive Test of } \\
\text { Phonological Processing (CTOPP; Wagner et al., 1998) }\end{array}$ & Reliability coefficient of .87 \\
\hline
\end{tabular}

c Intervention-based assessments: Finally, participants also completed intervention-based assessments. To assess participants' familiarity with the stimuli words prior to use in the intervention, familiarity was measured in an expressive, criterion referenced assessment at pre- and again at postassessment. For this expressive task, children were shown individual pictures of the target words and asked to define each word, similar to the method used in Justice et al. (2005).

A word can be known in varying degrees (Baumann and Kame'enui, 1991; Graves, 1984; McKeown and Beck, 1988; Nagy and Anderson, 1984). Beck et al. (1987) described three 'levels' of word knowledge:

1. unknown: basic meaning is completely unfamiliar;

2. acquainted: basic meaning is recognized after some thought; and

3. established: meaning is easily and rapidly recognized.

As Stahl (2003) indicates, for adults, it is not necessary to have full word knowledge ('established') in order to understand the meaning of the word in context. This suggests that for words with minimal knowledge, this knowledge can be used to make gross distinctions about a word's meaning. Curtis (1987) found that adults who reported only a partial knowledge of a word's meaning ('acquainted') could make a correct response to multiple-choice questions. It is important to consider emerging knowledge of a word (i.e. 'acquainted' word knowledge) as well as absolute knowledge of a word (i.e. 'established' word knowledge). Beck et al. (2002) indicated that using a child's definition as a measure or indication of level of word knowledge allows researchers to focus on the incremental movement towards a decontextualized understanding of a word.

Scoring for the expressive task involved the use of a rating scale. Participants received a ' 0 ' if their response represented minimal word knowledge (see Table 2 for scoring protocol), a ' 2 ' if their responses represented partial word knowledge, and a '4' if their responses represented full word knowledge. A total possible score of 80 could be achieved (i.e. 4 points $\times 20$ words). 
Table 2 Scoring protocol rubric

\begin{tabular}{|c|c|c|}
\hline Level of knowledge & Score & Example responses \\
\hline \multirow[t]{4}{*}{ Unknown } & 0 & No response. \\
\hline & & Incorrect definition (e.g. A thimble is a kind of ball.) \\
\hline & & Restatement (e.g. Car, car) \\
\hline & & Phonological manipulation (e.g. ladder, fatter) \\
\hline Partial Knowledge; & 2 & Appropriate use in a sentence or phrase (e.g. A duck was in the water) \\
\hline Beck et al.’s (1987) & & Incorrect or vague definition (e.g. A banjo sounds nice) \\
\hline "acquainted" level & & Imprecise synonym (e.g. Banjo, guitar) \\
\hline $\begin{array}{l}\text { Full Knowledge; Beck et al.'s } \\
\text { (1987) “established” level }\end{array}$ & 4 & $\begin{array}{l}\text { Precise definition (e.g. A tiger is an animal that has stripes and lives in } \\
\text { the jungle) and/or correct use in a sentence with definition included. }\end{array}$ \\
\hline
\end{tabular}

Source: Justice et al., 2005

Inter-rater reliability of the scoring protocol was established by randomly selecting 10 tests for independent scoring by a second trained coder. An item-by-item comparison was made of the original scoring and the scores of the second coder. For each test, an agreement percentage was calculated by dividing the total number of agreements by the number of agreements plus disagreements and multiplying this figure by 100 (Justice et al., 2005). Agreement scores for individual tests were from $88 \%$ (for those marked ' 2 '), $93 \%$ (for those receiving a ' 0 ') to $100 \%$ (for those receiving a ' 4 '), with a mean score of $93 \%$.

In addition to a rubric score, for ease of interpretation, a raw score is also reported. Words were scored as correct (1) if they received a ' 2 ' or a ' 4 ' on the rubric (indicating some or full word knowledge). Words were scored as incorrect ( 0 ) if they received a ' 0 ' on the rubric (indicating minimal word knowledge). In summary, two scoring systems were used to capture emerging (i.e. rubric score) and absolute word knowledge (i.e. binary, raw score).

\section{Procedures}

Following informed consent of participants and parents, the first author or a trained research assistant assessed participants individually. Test administration was conducted over two to four sessions within a two-week period to ensure optimal performance on all tasks. The study-specific measures were counterbalanced to control for order effects. After selecting the participants who met inclusionary criteria and completing the study-specific pre-assessments, intervention commenced. The two groups (typical vs. SSI) received intervention, with the focus on word learning, independent of each other. Students, within groups (i.e. typically developing and speech sound inaccuracies), were randomly assigned to a small group of five children. These five children then met twice each week for the intervention session. In total, there were 10 groups of children, with five in each group. Five of the groups were those who were typically developing and five of those groups were those with speech sound inaccuracies. Each group met twice weekly for a total of 11 weeks, with each session lasting approximately 30 minutes.

a Intervention stimuli: Each group heard the same researcher-generated storybooks, in the same presentation order, and the first author, who implemented the intervention, followed a standardized implementation protocol (detailed in the next section). Researcher-generated storybooks were used to control the vocabulary and also to assure that students were not previously familiar with the stories. 
Table 3 Intervention stimuli words

\begin{tabular}{lllll}
\hline Matched variables & Common-dense & Common-sparse & Rare-dense & Rare-sparse \\
\hline Early AoA, High Frequency & car & fish & pig & duck \\
Early AoA, Mid Frequency & pants & frog & dress & swing \\
Mid AoA, Mid Frequency & ladder & tiger & hammer & turtle \\
Mid AoA, Low Frequency & mitten & beaver & hanger & feather \\
Low AoA, Low Frequency & toaster & donkey & banjo & thimble \\
\hline
\end{tabular}

Notes: AoA = age of acquisition; frequency refers to frequency of occurrence

Source: words taken from Hoover et al., 2008; Maekawa and Storkel, 2005

Neighborhood density for stimuli words used in the intervention was computed for the stimuli in the speech sound accuracy measure using a 20,000 word computerized dictionary (Nusbaum et al., 1984), thought to be representative of the characteristics of American English. This has been used in other studies involving children (Storkel and Rogers, 2000). Density was calculated with the program, which identified the number of words differing from a given stimulus by a single phoneme.

Phonotactic probabilities were calculated by a program designed by Vitevitch and Luce (2004). The program is a web-based program that calculates the phonotactic probability of entered words. The guidelines set forth in Vitevitch and Luce (2004) for operationalizing the categories of low and high probability were used in this study (i.e. words with a probability below the 33rd percentile were marked as low phonotactic probability, and words above the 66th percentile were categorized as high phonotactic probability). To ensure that the participants could accurately produce the target sounds used in the stimuli, only words that included accurately produced sounds were included. Additionally, the words (see Table 3) were controlled for age of acquisition (Carroll and White, 1973), length in terms of syllables and segments, canonical structure, and frequency (Moe et al., 1982). The selected words have been validated in other research (Maekawa and Storkel, 2005).

Words that were targeted in the intervention sessions were balanced for density and probability. Words that were targeted included a balance of common-dense (more readily learned) and raresparse (less readily learned) (Storkel, 2001) in order to examine the impact word properties had on acquisition of new words and emergence of phonological awareness in this condition. Five commonsparse, five common-dense, five rare-sparse, and five rare-dense words were included. The order of presentation was counterbalanced across groups (typical vs. speech sound inaccuracies).

Intervention storybooks were created by the first author to house the new vocabulary terms within a familiar schema (storybook reading). Each storybook contained two of the targeted words, with four exposures per word. With two readings of the storybook a week, this meant eight exposures per word for all participants. This amount of exposure has been shown to be enough to facilitate change in children's knowledge (Storkel, 2001). The sentences for each targeted word were similar to ensure that the syntactic difficulty was equivalent across stories.

b Intervention procedure: All participants, regardless of group membership (i.e. typical or speech sound inaccuracies) received the same intervention with the same stories. The primary author followed a standardized implementation protocol (see Table 4). A story was read each week with an initial read aloud during the first session of the week and a repeated reading on the second session. The critical components of vocabulary instruction (Bauman et al., 2003) were incorporated into each session. These included multiple methods of instruction (direct and indirect), repetition and multiple exposure, and preinstruction of key words. Each session followed the same structure: 
Table 4 Standardized implementation protocol

\begin{tabular}{|c|c|}
\hline Component & Weekly activity/strategy \\
\hline $\begin{array}{l}\text { Pre-teach targeted } \\
\text { vocabulary }\end{array}$ & $\begin{array}{l}\text { Weeks I, 3, 5, 7, 9, II: Facilitate the creation of "kid friendly" definitions } \\
\text { with the students. Weeks 2, 3, 6, 8, I0: Word mapping or Frayer Model } \\
\text { (Frayer et al., 1969) }\end{array}$ \\
\hline $\begin{array}{l}\text { Read aloud of the } \\
\text { storybook }\end{array}$ & $\begin{array}{l}\text { Each session: Verbally highlight the targeted words. Confirm or refute } \\
\text { definitions created based on context. }\end{array}$ \\
\hline \multirow[t]{2}{*}{ Interactive learning } & Weeks I, 3, 5, 7, 9, II: Word detective (Gaskins et al., 1996). \\
\hline & Weeks $2,4,6,8,10$ : cloze procedure during reading with targeted words \\
\hline $\begin{array}{l}\text { Application of the } \\
\text { target words }\end{array}$ & $\begin{array}{l}\text { Each session: Receptive task: "I'm thinking of a word that means..." } \\
\text { Expressive task: "Use (target word) in a sentence" or "Tell me another } \\
\text { word for (target word). }\end{array}$ \\
\hline Concluding activity & $\begin{array}{l}\text { Weeks I, } 3,5,7,9,1 \text { I: Vocabulary dictionaries with graphic } \\
\text { representations of target words } \\
\text { Weeks } 2,4,6,8,10 \text { : Vocabulary charades or "I spy" }\end{array}$ \\
\hline
\end{tabular}

Note: This protocol was used for both groups across each book session.

1. preteaching of the key vocabulary words of the week;

2. interactive learning (e.g. study-specific storybook reading);

3. activities focused on learning and application of the target words; and

4. a concluding activity (e.g. graphic organizer, word map, etc.).

Within each storybook, the target words were contextualized through pictures. The text also provided definition-related support through the incorporation of synonyms and examples. For example, Sally's grandma put the thimble on her finger when she was sewing. A thimble is a cap or cover used to protect your finger when sewing. All definitions came from Merriam-Webster's Word Central (Merriam-Webster, 2008). Additionally, the reader (first author) provided opportunity for deep processing of the target words (Beck et al., 2008). That is, the reader provided opportunities for the children to actively make connections between the new words and words that they already knew and with situations they've encountered. For example, When have you worn a mitten? What was the weather like outside when you wore your mittens? These opportunities, while not part of the official text of the story, were incorporated into each book reading session for every group.

\section{Results}

\section{Group equivalency}

Equivalency of the two groups (typical vs. SSI) was examined at pretest across the following variables: chronological age, speech sound accuracy (standard score from GFTA-2), oral language (total language standard score from the $O W L S$ ), phonological awareness (phonological awareness subtest from CTOPP), vocabulary (standard scores from EVT and PPVT-3), and their raw scores from the pretest over the stimuli words. Comparison of the two groups is illustrated in Table 5 . Preliminary analyses of group differences revealed no statistically significant differences between the groups in chronological age, $F(1,48)=2.06, p=.16$, phonological awareness, $F(1,48)=3.75$, $p=.06$, expressive vocabulary, $F(1,48)=3.23, p=.08$, or receptive vocabulary, $F(1,48)=2.47$, $p=12$. Additionally, no group differences were found in preexisting knowledge of the stimuli words using the rubric data, $F(1,48)=.54, p=.47$, or the raw data, $F(1,48)=.66, p=.42$. There were 
Table 5 Descriptive statistics at pre-intervention

\begin{tabular}{|c|c|c|c|c|c|}
\hline \multirow[t]{2}{*}{ Variable } & \multicolumn{2}{|c|}{ Typical $(n=25)$} & \multicolumn{2}{|c|}{ SSI $(n=25)$} & \multirow[t]{2}{*}{ F statistic $(d f=I, 48)$} \\
\hline & M & SD & M & SD & \\
\hline Chronological age (months) & 75.4 & 3.3 & 74.1 & 3.1 & 2.06 \\
\hline PA & 102.4 & 14.2 & 95.4 & 11.2 & 3.75 \\
\hline EVT & 112.3 & 15.5 & 104.7 & 14.4 & 3.23 \\
\hline PPVT-III & 110.7 & 14.2 & 105.3 & 9.7 & 2.47 \\
\hline Target words (Emerging) & 53.4 & 7.6 & 51.1 & 8.9 & 0.97 \\
\hline Language & II5.| & 19.3 & 109.0 & 15.4 & 1.53 \\
\hline SSA & 107.4 & 11.3 & 81.6 & 10.7 & $68.71 * * *$ \\
\hline Target words (Absolute) & 11.2 & 3.2 & 10.5 & 2.0 & 0.66 \\
\hline
\end{tabular}

Notes: PA = phonological awareness composite score from CTOPP, EVT = standard score from Expressive Vocabulary Test, PPVT-III = standard score from Peabody Picture Vocabulary Test-III, Target words (emerging) = depth of word knowledge from rubric, Language $=$ Total Language composite standard score from OWLS, SSA = standard score from the Goldman Fristoe Test of Articulation-2, Target words (absolute) = binary data from the target word list. *** $p<.00 \mathrm{I}$.

group differences, as anticipated, in speech sound accuracy, $F(1,48)=68.71, p=.000$. There were no group differences in overall language, $F(1,48)=1.53, p=.22$.

\section{Nature of the relation between vocabulary and phonological awareness}

The first goal of the study was to examine the relation between vocabulary and phonological awareness in $\mathrm{K}-1$ children with and without speech sound inaccuracies. Specifically, does speech sound accuracy moderate the relation between vocabulary and phonological awareness skills? To determine this, hierarchical multiple regression analyses were used. To determine whether speech sound accuracy moderated the relation between vocabulary and phonological awareness, examination of the effects of an interaction term on the significance of the model occurred. The analyses determined whether the product of speech sound accuracy and vocabulary added anything to the model after vocabulary and speech sound accuracy were already in the equation. Results indicated that the overall model was statistically significant, $F(4,46)=10.52, p=.001$ (see Table 6 ). Both speech sound accuracy and vocabulary predicted unique variance in phonological awareness. The direction of the relationship is positive (as speech sound accuracy increases, so does phonological awareness and as vocabulary increases, so does phonological awareness). Additionally, the interaction term of speech sound accuracy and vocabulary was significant and accounted for an additional $5.1 \%$ of the variance in the model. Because the test of the interaction was significant, the effect of speech sound accuracy on phonological awareness is then described as a function of vocabulary and vice versa (i.e. the effect of vocabulary on phonological awareness is described as a function of speech sound accuracy). The effect of speech sound accuracy on phonological awareness is amplified as vocabulary increases. Increases in speech sound accuracy led to greater changes in phonological awareness as vocabulary increased. Likewise, the effect of vocabulary on phonological awareness was amplified as speech sound accuracy increases. Increases in vocabulary led to greater changes in phonological awareness as speech sound accuracy increased.

\section{Effect of word properties}

The second aim of this research was to determine whether word properties (i.e. phonotactic probability and neighborhood density) impact word learning in $\mathrm{K}-1$ children with and without speech sound 
Table 6 Predicting phonological awareness

\begin{tabular}{llllc}
\hline Predictor variable & $\mathrm{R}$ & $\Delta R 2$ & $\beta$ & $F$ value \\
\hline Model I: & .56 & .418 & & $11.43^{* * *}$ \\
Speech sound accuracy & & .151 & .284 & $3.56^{* *}$ \\
Vocabulary & & .211 & .481 & $4.12^{* *}$ \\
Model 2 & .62 & .493 & & $10.52^{* * *}$ \\
Speech sound accuracy & & .142 & .214 & $2.74^{*}$ \\
Vocabulary & & .201 & .415 & $2.82^{*}$ \\
SSA $\times$ vocabulary & .051 & .124 & $2.59 *$ \\
\hline
\end{tabular}

Notes: df for Model I $(3,47)$, for Model $2(4,46){ }^{*} p<.05$, ** $p<.0$ I, *** $p<.00$ I.

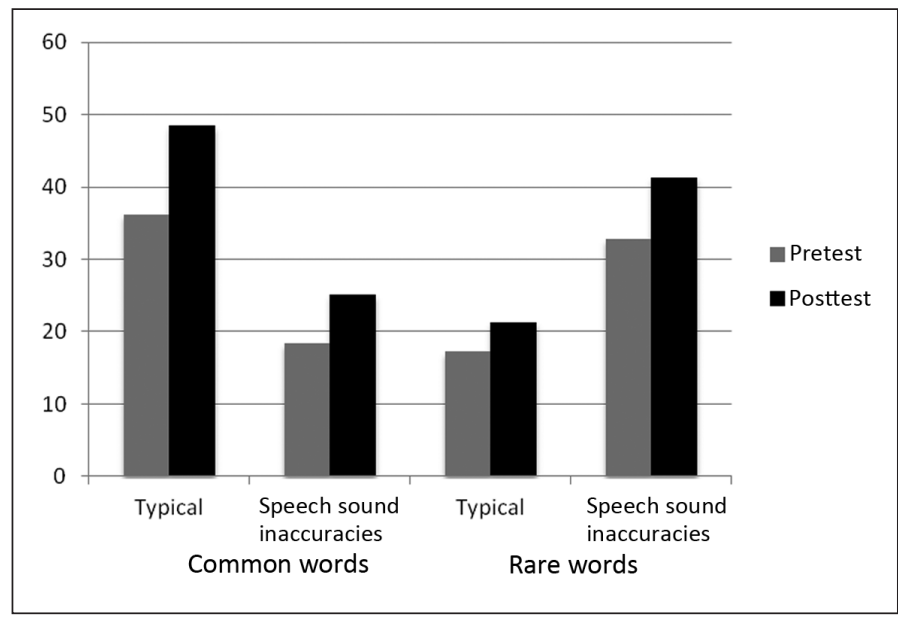

Figure I Growth in word knowledge using rubric data by group and phonotactic probability

inaccuracies. To examine the magnitude of word learning gains made by each group, gains from pretest to posttest were examined, using absolute word knowledge data. On average, the entire group of children gained 6.3 points (which equates to approximately 6 words). Overall, gains were equivalent across groups $(M=7.8, S D=4.6$ for typically developing and $M=5.6, S D=5.2$ for those in the SSI group), $\mathrm{t}(48)=1.33, p=.189$.

To examine group differences in word learning, a 2 (group) $\times 2$ (phonotactic probability) $\times 2$ (density) repeated measures ANOVA was completed using emerging word knowledge rubric data from the 20 stimuli words. Results indicated that there was a significant main effect for group, $F(2,48)=7.55, p<.008(d=.78)$. In general, children in the typical group $(M=71.4, S D=11.3)$ scored more points on the emerging word knowledge rubric than children in the SSI group $(M=62.3$, $S D=12.1)$. There was a significant phonotactic probability $\times$ group interaction, $F(2,48)=4.83$, $p=.012$. This indicated that there were group differences in the use of or preference for phonotactic probabilities (see Figure 1). Students in the typically developing group gained more points on the emerging word knowledge rubric for words with common sound sequences $(M=12.2, S D=3.4)$ over those with rare sound sequences $(M=5.8, S D=4.1)$. For children in the group with SSI, greater gains were made for words with rare sound sequences $(M=8.5, S D=3.3)$ over those with common sound sequences $(M=5.6, S D=4.2)$. Table 7 illustrates statistical analysis of the differences in word knowledge based on emerging word knowledge data. 
Table 7 Growth in word knowledge using rubric data by group and probability

\begin{tabular}{lrrr}
\hline Group & M & SD & F $(I, 48)$ \\
\hline Common probability: & 12.2 & & 24.97 **** \\
Typical & 5.6 & 3.4 & \\
SSI & & 4.2 & \\
Rare probability: & 4.1 & 3.2 & $22.91 * * *$ \\
Typical & 8.5 & 3.3 & \\
SSI &
\end{tabular}

Notes: SSI = group with speech sound inaccuracies, $*^{* *} p<.001$

Table 8 Growth in word knowledge using rubric data by group and density

\begin{tabular}{lccc}
\hline Group & M & SD & $\mathrm{F}(1,48)$ \\
\hline Dense neighborhood: & & & \\
Typical & 5.7 & 3.1 & $46.59 * * *$ \\
SSI & 14.2 & 5.4 & \\
Sparse neighborhood: & & & $11.09 * *$ \\
Typical & 13.7 & 5.1 & \\
SSI & 9.3 & 4.2 & \\
\hline
\end{tabular}

Notes: SSI = group with speech sound inaccuracies, ${ }^{* * *} p<.00 \mathrm{I}, * * p<.0 \mathrm{I}$

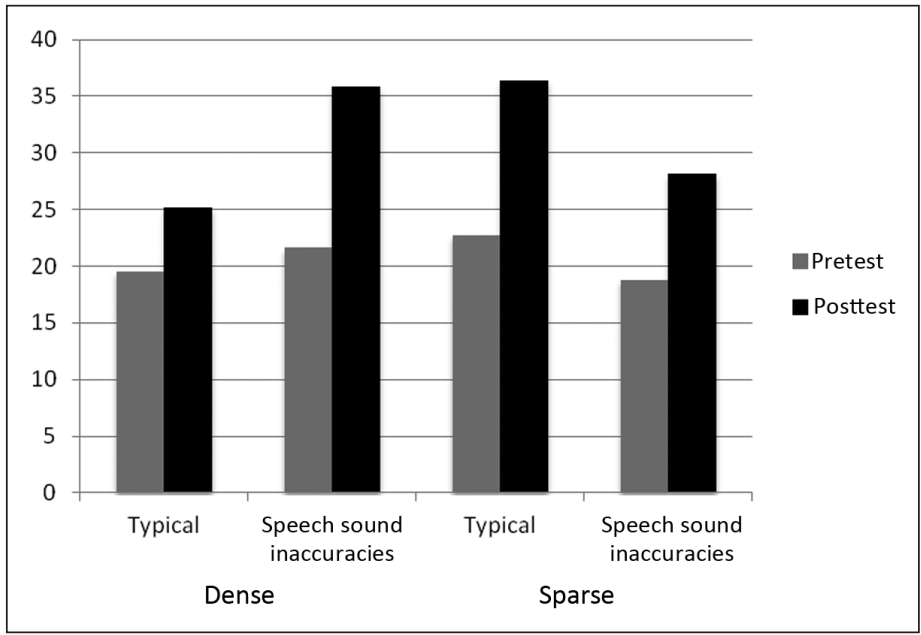

Figure 2 Growth in word knowledge using rubric data by group and density

There was also a significant neighborhood density $\times$ group interaction, $F(2,48)=3.64, p=.033$. This indicated that there were group differences in the use of or preference for neighborhood density (see Table 8). Students in the typically developing group gained more points on the emerging word knowledge rubric on words from sparse neighborhoods whereas, children in the group with SSI gained more points on the emerging word knowledge rubric on words from dense neighborhoods (see Figure 2). 


\section{Discussion}

To summarize the results of this study, the first major finding was that speech sound accuracy and vocabulary each predicted unique variance in phonological awareness in $\mathrm{K}-1$ children with and without speech sound inaccuracies. Additionally, the two skills appeared to moderate effect of each on phonological awareness. The second major finding was that no group differences emerged in the absolute number of words that participants learned over the course of the study. However, when taking into account emerging knowledge (per the rating scale data), children in the typically developing group showed significantly greater gains in the word knowledge from pretest to posttest than did children with speech sound inaccuracies. The third major finding was demonstration of differences between the groups in how word properties impacted word learning. For the children in the typically developing group, words that had a common probability were learned over words with rare probability. Additionally, they scored more points for words from sparse neighborhoods at posttest than for words from dense neighborhoods. Interestingly, the exact opposite was found in the group of children with speech sound inaccuracies. These children learned words with rare probability over words with common probability. Additionally, they learned words from dense neighborhoods over words from sparse neighborhoods.

\section{Speech sound accuracy and vocabulary as predictors of phonological awareness}

Our findings lend support to extant research that has indicated that there are concurrent associations between a child's vocabulary skills and his/her phonological awareness skills (Cooper et al., 2002; McDowell, 2004). Second, our findings support the research that has indicated that children with deficits in speech sound accuracy may be at-risk for reading-related skills (Bird et al., 1995), as speech sound accuracy predicted unique variance in phonological awareness skills. It is thought that children with speech sound inaccuracies or delays may have different underlying phonological representations compared to typically developing peers (McDowell et al., 2007). These differences in underlying, sublexical representations may limit or hinder these children's abilities to acquire new words or to attend to and manipulate the phonological units.

\section{Group differences in word learning}

Our results indicate that children across both groups learned an equivalent number of words during the storybook intervention, when measured in absolute terms (i.e. correct or incorrect). However, research has indicated that vocabulary learning is not an 'all or known' phenomenon. There are levels of word knowledge (Nagy and Hermann, 1987). Using the rubric data in analyses provided us with a glimpse of emerging knowledge. Our results indicate that although no statistically significant differences were found between the groups in terms of absolute number of words learned, there were differences in the sense that typically developing children were developing an emerging level of word knowledge greater than children with speech sound inaccuracies. Our findings extend those of Storkel et al. (2007), who found group differences in word learning within an immediate word learning task, with typically developing preschoolers outperforming children with speech sound deficits. Our study indicates that this pattern continues into early elementary grades (i.e. $\mathrm{K}-1$ ). Our findings are in contrast to those reported by Maekawa and Storkel (2005), who found no group differences in word learning.

There are a few possible explanations for our findings, in relation to current research. Previous research was conducted using preschool students. This research was conducted using $\mathrm{K}-1$ students. Preschool research has indicated that there may be group differences in the magnitude of words 
learned given the type of time constraint placed on learning (Storkel, 2005; Storkel et al., 2007). In their short-term word learning tasks (typically occurring within the context of a game-based format, with referents, using non-words), preschool children who have typically developing speech skills tend to learn more words than children with phonological disorders (Storkel et al., 2007). For longterm word learning tasks (typically measured one week post intervention), they reported no group differences in word learning (Hoover et al., 2008). Our findings provide support for and extend to an older group of children, for both of these notions, depending upon the data used. If examining absolute number of words learned, our findings with $\mathrm{K}-1$ students support and extend to early elementary students the notion of no group differences (Hoover et al., 2008; Maekawa and Storkel, 2005). However, using the rubric data that indicated an emerging level of word knowledge, our findings offer support to and extend to early elementary students (i.e. $\mathrm{K}-1$ ) the notion of group differences in word learning between children who are typically developing and children with speech sound deficits (Storkel et al., 2007).

\section{Word properties: Differential effects}

Our study yielded interesting results regarding word properties and their influence on word learning in kindergarten and first grade children. Results indicated that typically developing children in our study learned more words with common phonotactic probabilities and from sparse neighborhoods than those in the SSI group. In complete contrast, students in the SSI group learned more words with rare phonotactic probabilities and from dense neighborhoods. Extant literature has indicated that word properties can impact word learning (e.g. Maekawa and Storkel, 2005). Our study supports this notion and extends findings to a novel age group, early elementary students.

The results can be looked at from a different perspective, again, as Storkel often does, in terms of time constraints within learning. For short-term word learning, children with speech sound inaccuracies often prefer words from dense neighborhoods vs. sparse neighborhoods (Hoover et al., 2008), with both groups (typically developing and those with speech sound inaccuracies) preferring common probability over rare. In contrast, for long-term word learning, both typically developing children and children with speech sound inaccuracies preferred words from dense neighborhoods vs. sparse neighborhoods. Additionally, group differences in preferences for phonotactic probability emerged, with typically developing children retaining a preference from words with common phonotactic probabilities (Storkel et al., 2006). Children with speech sound inaccuracies did not demonstrate a residual effect of phonotactic probability in long-term word learning (Storkel et al., 2006). Our results are in conflict with this finding. Our results indicate that, in long-term word learning (the duration of our intervention was 11 weeks, making it similar to Storkel's long-term word learning tasks), there is an interaction between group and probability, with typically developing children preferring words with common phonotactic probabilities, and children with speech sound inaccuracies preferring words with rare phonotactic probabilities.

There are a few possible explanations for the differences in findings. First, age-related differences have been reported (Hoover and Storkel, 2007). In a preschool sample, word properties had no significant effect on 3-year-olds' word learning. For 4-year-olds, a significant effect was found for neighborhood density but not for phonotactic probability. For 5-year-olds, a significant effect was found for phonotactic probability but not for neighborhood density. Hoover and Storkel indicated that the use of phonological (sublexical) and lexical cues in word learning change in the preschool years. Perhaps, too, those changes continue into the early elementary school years, as evidenced in our findings.

Studies that have examined word properties in adult word knowledge have indicated that phonotactic probability impact adults' ability to read non-words (Vitevitch and Luce, 2005) and to name pictures 
(Vitevitch et al., 2004) with words with high phonotactic probability being said or read more quickly than those with low probability. Additionally, words with sparse onsets were named more rapidly than words with dense onsets (an effect of neighborhood density). For typically developing individuals, it appears as though both sublexical and lexical information are used when learning new words and that a preference is seen for common phonotactic probability over rare (Hoover et al., 2008; Storkel et al., 2006) and for words from dense neighborhoods over sparse (Hoover et al., 2008). However, certain factors influence these findings, such as time constraint of word learning (short vs. long term).

For children with speech sound inaccuracies, this pattern appears to differ. It appears as though they prefer words from dense neighborhoods and with rare phonotactic probabilities. However, most recently, Lee and Storkel (2008) reported a variable effect of phonotactic probability within preschool children with speech sound inaccuracies. Half of their sample performed similarly to the typically developing children (i.e. high effect). This was attributed to the predictability of phonological sequences and frequency of occurrence (Storkel and Rogers, 2000). The other half of their sample demonstrated the opposite effect (i.e. low effect), similar to our findings. This could be attributed to the notion that children with speech sound impairments rely, as Storkel (2004) has indicated, more heavily on lexical representations (as measured by neighborhood density) to learn novel words and that they may have difficulty learning sound sequences with common probabilities due to the high degree of commonality between these sound sequences and other known words.

Another possible explanation for differences in findings stems from stimuli selection. In our study and that of Justice et al. (2005), real words were utilized. In other studies (Hoover et al., 2008; Storkel, 2004), non-words were used. Within a psycholinguistic model of speech processing, non-words potentially tap phonological processing below the level of the semantic and phonological lexicons (Gates et al., 2009). Using non-words theoretically taps into the sublexical representation, and typically results in a phonotactic probability effect. Using real words theoretically taps into the lexical representation, and typically results in a neighborhood density effect. Vitevitch (2003) had adults complete spoken word recognition tasks under varying conditions of words and non-words. Results supported the sublexical/lexical effect. More specifically, the results suggest that under typical processing situations, where words from our native language are heard, reliance on lexical representations is typical. However, Vitevitch (2003) found subsets of individuals who were either lexical or sublexical processors under the real word condition. This suggests that individual differences may play a role in word knowledge. Results from our study indicate that $\mathrm{K}-1$ children, when learning new words, use both lexical and sublexical representations but that these differ based on speech sound accuracy.

What is missing from extant literature is a longitudinal view of the types of cues and patterns of usage that children with speech sound inaccuracies rely upon. Our study indicates that for early elementary children with speech sound inaccuracies, words from dense neighborhoods are preferred over words from sparse and that words with rare probabilities are preferred over those with common probabilities. As Storkel has indicated (Storkel et al., 2007), productive phonology (i.e. speech sound accuracy) may influence immediate processing of novel words.

\section{Limitations and future research}

There are a few limitations to the current study. First, ceiling effects were noted for some of the stimuli words. The word list was chosen because (1) it had been validated in other research (Hoover et al., 2008; Maekawa and Storkel, 2005), and (2) it was balanced for age of acquisition, frequency of occurrence, density, and phonotactic probability. However, looking at the words in terms of 'robust vocabulary' (Beck et al., 2002), the words could be classified as Tier One words. Future research 
could focus on the use of Tier Two words balanced for the same word properties. Another limitation to this research was the intervention-specific stimuli assessment (i.e. expressive word knowledge rubric). Although this rubric gave us a glimpse of an emerging sense of expressive word knowledge, it did not assess receptive vocabulary understanding. As Sénéchal (1997) indicated, receptive knowledge of words tends to occur prior to expressive knowledge. As a result, participants' vocabulary knowledge may have been underestimated. Finally, we did not distinguish between students with speech sound inaccuracies and those with delayed or disordered speech. Inaccuracies in speech sound production do not necessarily equate to disordered speech. Results may have differed if we had only included those with speech sound disorders (e.g. Dodd and Bradford, 2000).

Results from our study support those of Justice et al. (2005), who reported that storybook-based interventions were effective at promoting word learning growth in at-risk kindergarten children. They included at-risk kindergarten children with low vocabulary skills. Our study extends those findings to indicate that this type of intervention also shows promise for children with speech sound inaccuracies. Future research is needed in terms of the types of storybooks that promote the most change within word learning. Justice et al. (2005) used published storybooks, readily available to teachers, making the intervention user-friendly. Our study, given that we intentionally manipulated the word properties of the key stimuli words, used researcher-generated storybooks.

These limitations and the key findings of this study suggest several important areas of further research. According to Storkel (2004), 'future work is needed to examine the composition of the lexicon of children with phonological disorders and its association with the development of phonological awareness' (p. 1209). Clearly needed is longitudinal data on the use of sublexical and lexical cues in word learning by children with speech sound inaccuracies. The current study indicates that early elementary students with SSI may be at-risk for poor phonological awareness skills (as speech sound accuracy predicted unique variance in phonological awareness), and that they may learn different kinds of words compared to typically developing children; these are critical findings for both kindergarten and first grade classroom teachers. This has implications for intervention materials for children with speech sound deficits. If we want to promote change within the sublexical domain (i.e. phonology system), we may want to focus on words with rare sound sequences. If we want to promote change within the lexical domain (i.e. word level), we may want to focus on words from dense neighborhoods.

\section{Clinical implications}

One limitation of previous work examining vocabulary skills, phonological awareness, and speech sound accuracy is the exclusion of school-age children with exceptionalities. There are reports indicating the nature of the relations among these skills in children who are typically developing (Lonigan, 2006); however, children with speech sound inaccuracies have often not been included. It has been suggested that similarity to other words may facilitate changes in lexical representations that subsequently facilitate emergence of phonological awareness (Metsala and Walley, 1998). If children with speech sound inaccuracies are slower to learn phonologically similar words (Storkel, 2004), they may be at risk for later phonological awareness difficulties. This, in turn, indicates that we need to be targeting words that will be facilitative in producing changes not only in the child's phonological system (sublexical) but also in the child's semantic system.

\section{Acknowledgements}

Thank you to the American Speech Language Hearing Foundation for providing funding for this project. 


\section{References}

Anglin JM (1993) Vocabulary development: A morphological analysis. Monographs of the Society for Research in Child Development 58(10), serial number 238.

Baumann JF and Kame'enui EJ (1991) Research on vocabulary instruction: Ode To Voltaire. In: Flood J, Lapp JJ, and Squire JS (eds) Handbook of research on teaching the English language arts. New York: MacMillan, 604-32.

Bauman JF, Kame'enui EJ, and Ash G (2003) Research on vocabulary instruction. In: Fllod J, Lapp D, Squire JR, and Jenson J (eds) Handbook of research on teaching the language arts. 2nd edition. Mahwah, NJ: Lawrence Erlbaum, 752-85.

Beck IL, McKeown MG, and Kucan L (2002) Bringing words to life. New York: Guilford Press.

Beck IL, McKeown MG, and Kucan L (2008) Creating robust vocabulary: Frequently asked questions and extended examples. New York: Guilford Press.

Beck IL, McKeown MG, and Omanson RC (1987) The effects and uses of diverse vocabulary instructional techniques. In McKeown MG and Curtis ME (eds) The nature of vocabulary acquisition. Hillsdale, NJ: Erlbaum, 147-63.

Bird J, Bishop D, and Freeman N (1995) Phonological awareness and literacy development in children with expressive phonological impairments. Journal of Speech and Hearing Research 38: 446-62.

Carrol JB and White MN (1973) Word frequency and age of acquisition as determiners of picture-naming latency. Quarterly Journal of Experimental Psychology 25: 85-95.

Carrow-Woolfolk E (1995) Oral and written language scales. Circle Pines, MN: American Guidance Services.

Cooper DH, Roth FP, Speece DL, and Schatschneider C (2002) The contribution of oral language skills to the development of phonological awareness. Applied Psycholinguistics 23: 399-416.

Coyne MD, McCoach DB, and Kapp S (2007) Vocabulary intervention for kindergarten students: Comparing extended instruction with embedded instruction and incidental exposure. Learning Disabilities Quarterly 30: 74-88.

Coyne MD, Simmons DC, Kame'enui EJ, and Stoolmiller M (2004) Teaching vocabulary during shared storybook readings: An examination of differential effects. Exceptionality 12: 145-62.

Crain-Thorenson C and Dale P (1999) Enhancing linguistic performance: Parents and teachers as book reading partners for children with language delays. Topics in Early Childhood Special Education 19: 28-43.

Curtis ME (1987) Vocabulary testing and vocabulary instruction. In: McKeown MG and Curtis ME (eds) The nature of vocabulary acquisition. Hillsdale, NJ: Erlbaum.

Dodd B and Bradford A (2000) A comparison of three therapy methods for children with different types of developmental phonological disorder. International Journal of Communication Disorders 35: 189-209.

Dunn L and Dunn L (1997) Peabody picture vocabulary test-3. Circle Pines, MN: American Guidance Service.

Edwards J, Fox RA, and Rogers CL (2002) Final consonant discrimination in children. Journal of Speech, Language, and Hearing Research 45: 231-42.

Elbro C (1996) Early linguistic abilities and reading development: A review and a hypothesis. Reading and Writing: An Interdisciplinary Journal 8: 453-85.

Frayer D, Frederick WC, and Klausmeier HJ (1969) A schema for testing the level of cognitive mastery. Madison, WI: Wisconsin Center for Education Research.

Gaskins IW, Ehri LC, Cress C, O'Hara C and Donnelly K (1996) Procedures for word learning: Making discoveries about words. The Reading Teacher 50, 312-27.

Gates S, Rosen S, and Vance M (2009) A production-perception link? Phonological processing in typically developing children. Retrieved from http://www.chc.ucl.ac.uk/phonology/SophieGATES.pdf(December 2011)

Gillon GT (2000) The efficacy of phonological awareness intervention for children with spoken language impairment. Language, Speech, and Hearing Service in Schools 31: 126-41.

Goldman R and Fristoe M (2000) Goldman Fristoe test of articulation-2. Circle Pines, MN: American Guidance Services.

Hargrave AC and Sénéchal M (2000) Book reading interventions with language-delayed preschool children: The benefits of regular reading and dialogic reading. Early Childhood Research Quarterly 15: 75-90. 
Hoover JR and Storkel HL (2007) Phonological and lexical cues in word learning by preschool children. With McGregor K, Gray S, Alt M, Munson B, and Hogan T, in seminar entitled: Word learning in situ: Interplay between learners and learning environments. Presented at the American Speech-Language-Hearing Association Convention, Boston, MA, USA.

Hoover JR, Storkel HS, and Maekawa J (2008) The effect of delayed phonological development on sublexical and lexical processing in preschool children. With Hoff E, Oller DK, Ratner N, and Stoel-Gammon C, in seminar entitled: How phonological development supports lexical development. Presented at the XI Congress of the International Association for the Study of Child Language, Edinburgh, UK.

Justice LM and Ezell HK (2002) Enhancing children's print and word awareness through home-based parent intervention. American Journal of Speech-Language Pathology 9: 257-96.

Justice LM, Meier J, and Walpole S (2005) Learning new words from storybooks: An efficacy study with at-risk kindergarteners. Language, Speech, Hearing Services in Schools 36: 17-32.

Kaderavek J and Justice LM (2002) Shared storybook reading as an intervention context: Practices and potential pitfalls. American Journal of Speech-Language Pathology 11: 395-406.

Lee SY and Storkel HL (2008) Phonological and lexical characteristics. Unpublished paper presented at the American Speech-Language-Hearing Association Convention, Chicago, IL, USA.

Lonigan CJ (2006) Development, assessment, and promotion of preliteracy skills. Early Education and Development 17: 91-114.

Lonigan CJ and Whitehurst GJ (1998) Relative efficacy of parent and teacher involvement in a shared-reading intervention for preschool children from low-income backgrounds. Early Childhood Research Quarterly 13: 263-90.

Lonigan CJ, Burgess S, Anthony J, and Barker T (1998) Development of phonological sensitivity in 2- to 5-year old children. Journal of Educational Psychology 90: 294-311.

Luce PA and Pisoni DB (1998) Recognizing spoken words: The neighborhood activation model. Ear and Hearing 19: 1-36.

Maekawa J and Storkel HL (2005) Word learning II: Naturalistic learning by children with phonological delays. Unpublished paper presented at American Speech-Language-Hearing Association Convention, San Diego, CA, USA.

McDowell K (2004) Examining relations among expressive phonology, phonological processing, and early decoding skills in children. Unpublished doctoral dissertation, Florida State University, FL, USA.

McDowell K, Lonigan CJ, and Goldstein H (2007) Relations among SES, age, and predictors of phonological awareness. Journal of Speech, Language, and Hearing Research 50: 1079-92.

McKeown MG and Beck IL (1988) Learning vocabulary: Different ways for different goals. Remedial and Special Education 20: 482-96.

Mendelsohn AL, Mogilner LN, Dreyer BP, Forman JA, Weinstein SC, Broderick M, Cheng KJ, Magloire T, Moore T, and Napier C (2001) The impact of a clinic-based literacy intervention on language development in inner-city preschool children. Pediatrics 107: 130-34.

Merriam-Webster (2008) Word central. Springfield, MA: Merriam-Webster. Retrieved from: http://www. wordcentral.com (December 2011).

Metsala JL (1997) An examination of word frequency and neighborhood density in the development of spoken word recognition. Memory and Cognition 25: 47-56.

Metsala J and Walley A (1998) Spoken vocabulary growth and segmental restructuring of lexical representations: Precursors to phonemic awareness and early reading ability. In: Metsala J and Ehri L (eds) Word recognition in beginning reading. Mahwah, NJ: Lawrence Erlbaum, 89-120.

Moe AJ, Hopkins KJ, and Rush RT (1982) The vocabulary of first grade children. Springfield, IL: Thomas.

Nagy WE and Anderson R (1984) How many words are there in printed school English. Reading Research Quarterly 19: 304-30.

Nagy WE and Hermann PA (1987) Breadth and depth of vocabulary knowledge: Implications for acquisition and instruction. In: McKeown MG and Curtis ME (eds) The nature of vocabulary acquisition. Hillsdale, NJ: Erlbaum Associate, 19-35.

National Reading Panel (2000) Report of the national reading panel: Teaching children to read. Washington, DC: U.S. Department of Health and Human Services. 
Nusbaum HC, Pisoni DB, and Davis DK (1984) Sizing up the Hoosier mental lexicon. Research on Spoken Language Processing Report No. 10. Bloomington, IN: Speech Research Lab, Indiana University, 357-76.

Raz IT and Bryant P (1990) Social background, phonological awareness, and children's reading. British Journal of Developmental Psychology 8: 209-25.

Roth FP, Speece DL, and Cooper DH (2002) A longitudinal analysis of the connection between oral language and early reading. The Journal of Educational Research 95: 259--72.

Rvachew S, Nowak M, and Cloutier G (2004) Effect of phonemic perception training on the speech production and phonological awareness skills of children with expressive phonological delay. American Journal of Speech-Language Pathology 13: 250-63.

Sénéchal M (1997) The differential effect of storybook reading on preschooler's expressive and receptive vocabulary acquisition. Journal of Child Language 24: 123-38.

Sénéchal M and Lefevre J (2002) Parental involvement in the development of children's reading skills: A 5-year longitudinal study. Child Development 73: 445-60.

Shriberg LD, Kwiatkowski J, Best S, Hengst J, and Terselic-Weber B (1986) Characteristics of children with phonological disorders of unknown origin. Journal of Speech and Hearing Disorders 51: 140-61.

Stahl KAD (2003) Vocabulary development and word walls in the primary classroom. Unpublished address presented at the Georgia Department of Education, REA Best Practices Institute Statesboro, GA, USA.

St Louis KO and Ruscello DM (2000) Oral speech mechanism screening examination-3. Hydesville, CA: Psychological and Educational Assessments.

Storkel HL (2001) Learning new words: Phonotactic probability in language development. Journal of Speech, Language, and Hearing Research 44: 1321-37.

Storkel HL (2002) Restructuring of similarity neighborhoods in the developing mental lexicon. Journal of Child Language 29: 251-4.

Storkel HL (2004) The emerging lexicon of children with phonological delays: Phonotactic constraints and probability in acquisition. Journal of Speech, Language, and Hearing Research 47: 1194-1212.

Storkel HL (2005) The mental lexicon in acquisition. Unpublished paper presented to the National Institute on Deafness and Other Communication Disorders Advisory Council Meeting, Bethesda, MD, USA.

Storkel HL and Morrisette ML (2002) The lexicon and phonology: Interactions in language acquisition. Language, Speech, and Hearing Services in Schools 33: 24-37.

Storkel HL and Rogers MA (2000) The effect of probabilistic phonotactics on lexical acquisition. Clinical Linguistics and Phonetics 14: 407-25.

Storkel HL, Hoover JR, and Maekawa J (2006) Representations involved in short-term versus long-term word learning by preschool children with and without phonological disorders. Unpublished paper presented at the Fourth Joint Meeting of the Acoustical Society of America and the Acoustical Society of Japan, Honolulu, HI, USA.

Storkel HL, Hoover JR, and Maekawa J (2007) Predicting word learning by preschool children with phonological delays. Unpublished paper presented at the American Speech-Language-Hearing Association Convention, Boston, MA, USA.

Vitevitch MS (2003) The influence of sublexical and lexical representations on the processing of spoken words in English. Clinical Linguistics and Phonetics 17: 487-99.

Vitevitch MS and Luce PA (1998) When words compete: Levels of processing in spoken word perception. Psychological Science 9: 325-29.

Vitevitch MS and Luce PA (1999) Probabilistic phonotactics and neighborhood activation in spoken word recognition. Journal of Memory and Language 40: 374-408.

Vitevitch MS and Luce PA (2004) A web-based interface to calculate phonotactic probability for words and nonwords in English. Behavior Research Methods, Instruments, and Computers 36: 481-87.

Vitevitch MS and Luce PA (2005) Increases in phonotactic probability facilitate spoken nonword repetition. Journal of Memory and Language 52: 193-204.

Vitevitch MS, Armbruster J, and Chu S (2004) Sub-lexical and lexical representations in speech production: Effects of phonotactic probability and onset density. Journal of Experimental Psychology: Learning, Memory, and Cognition 30: 514-29. 
Wagner RK and Torgesen JK (1987) The nature of phonological processing and its causal role in the acquisition of reading skills. The Psychological Bulletin 101: 192-212.

Wagner RK, Torgesen JK, and Rashotte CA (1998) Comprehensive test of phonological processing. Circle Pines, MN: American Guidance Services.

Walley AC, Metsala JL, and Garlock VM (2003) Spoken vocabulary growth: Its role in the development of phoneme awareness and early reading ability. Reading and Writing: An Interdisciplinary Journal 16: 5-20.

Weschler D (2002) Weschler preschool and primary scale of intelligence. 3rd edition. San Antonio, TX: Psychological Corporation.

Whitehurst GJ, Arnold DS, Epstein JN, Angell AL, Smith M, and Fischel JE (1994) A picture book reading intervention in day care and home for children from low-income families. Developmental Psychology 30: 679-89.

Williams K (1997) Expressive vocabulary test. Circle Pines, MN: American Guidance Services.

Ziolkowski RA and Goldstein H (2008) Effects of an embedded phonological awareness intervention during repeated book reading on preschool children with language delays. Journal of Early Intervention 31: 67-90. 